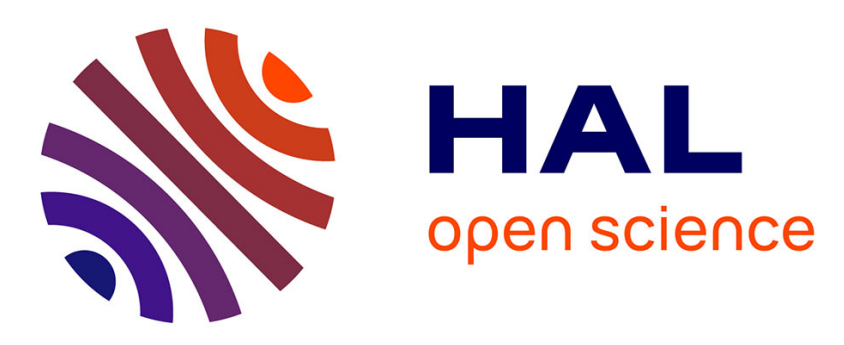

\title{
Induction Heating of Aluminum Billets With Linear Motion in a Strong DC Magnetic Field: Magnetothermal Analysis in Two-Dimensional
}

Hakim Bensaidane, Youcef Ouazir, Thierry Lubin, Smail Mezani, Abderrezak Rezzoug

\section{- To cite this version:}

Hakim Bensaidane, Youcef Ouazir, Thierry Lubin, Smail Mezani, Abderrezak Rezzoug. Induction Heating of Aluminum Billets With Linear Motion in a Strong DC Magnetic Field: Magnetothermal Analysis in Two-Dimensional. IEEE Transactions on Applied Superconductivity, 2011, 21 (4), pp.34793487. 10.1109/TASC.2011.2144979 . hal-00640598

\section{HAL Id: hal-00640598 https://hal.science/hal-00640598}

Submitted on 13 Nov 2011

HAL is a multi-disciplinary open access archive for the deposit and dissemination of scientific research documents, whether they are published or not. The documents may come from teaching and research institutions in France or abroad, or from public or private research centers.
L'archive ouverte pluridisciplinaire HAL, est destinée au dépôt et à la diffusion de documents scientifiques de niveau recherche, publiés ou non, émanant des établissements d'enseignement et de recherche français ou étrangers, des laboratoires publics ou privés. 


\title{
Induction Heating of Aluminium Billets with linear motion in a Strong DC Magnetic Field: Magneto-Thermal Analysis in 2D
}

\author{
Hakim Bensaidane, Youcef Ouazir, Thierry Lubin, Smail Mezani, and Abderrezak Rezzoug
}

\begin{abstract}
This paper presents a new structure of an induction heater for aluminium billets. The device consists in using a strong DC magnetic field created by a superconducting inductor in which the conducting billet is actuated by a linear motion at a constant velocity. The analysis, based on the analytical model for the magnetic field in the billet, has been developed, and then the eddy currents and induced heating power have been evaluated. The analytical results are compared to those issued from a finite element software (COMSOL). The magneto thermal analysis shows that the temperature profile in the billet is homogenous.
\end{abstract}

Index Terms-Induction heater, analytical solution, eddy current, induced heating power, linear motion, superconducting, magneto-thermal

\section{INTRODUCTION}

$\mathbf{I}^{\mathrm{N}}$ NDUCTION heating is widely used in industrial processes to preheat aluminium billets before press-forming operations [1]. The analysis of induction heating requires the development of simulation and modeling tools. It depends on several physical phenomena: electromagnetic, thermal, and mechanical ones.

In conventional induction heaters, the billet is exposed to an AC magnetic field produced by a water-cooled copper winding. The thermal power is due to the eddy currents induced in the billet. It is well known that the efficiency of the process is related to the power transferred from the inductor to the billet. The efficiency depends on the resistivity and the magnetic permeability of the material to be heated. For magnetic steel billets, the efficiency is in the range of 80 to 90\% below the Curie temperature and remains relatively important (approximately 70\%) above this temperature when steel becomes nonmagnetic [1]. In the same way, the efficiency of an induction heater for nonmagnetic metal billets (aluminium and Copper) drastically drops to about 50\%. In fact, it is difficult to heat nonmagnetic conducting materials

Manuscript received February 4, 2011.

H. Bensaidane and Y. Ouazir are with the University of science and technology (USTHB), BP N ${ }^{\circ} 32$ El Alia Bab Ezzouar, Algiers, Algeria (phone: +213661 4655 15; fax: +213 212471 87; e-mail: hakimbensaidane@ yahoo.fr and youazir@yahoo.fr).

T. Lubin, S. Mezani and A. Rezzoug are with GREEN-UHP, Faculté des Sciences et Technologies, BP 239, 54506, Vandouvre-lès-Nancy, France (email: Thierry.Lubin@green.uhp-nancy.fr). with conventional heating devices.

In order to improve the efficiency, Runde and Magnusson [2]-[4] have proposed a new type of induction heater by replacing the conventional copper inductor by a hightemperature superconducting (HTS) coil excited with $50 / 60 \mathrm{~Hz}$ AC current. However, because of the AC losses in the HTS coil, the efficiency obtained with a small-scale demonstrator does not exceed 60\% [4]. More recently, a new DC induction heating concept with a superconducting coil has been proposed. In this approach, the billet is rotated inside a transverse DC magnetic field generated by superconducting coils [5]-[7]. Velocity induced currents react to the driving torque and generates a thermal power within the billet [8]-[9].

In this paper, we develop an electromagnetic and thermal analysis of an original induction heater for aluminium billets using superconducting coils. In this topology, the billet is subjected to a linear motion inside a strong DC magnetic field produced by a superconducting inductor. The topology described here was in its principle, patented independently by Magnusson [10] and Müller et al. [11]. The description of the studied induction heater is given in section II. An analytical electromagnetic model is then developed in section III and IV to find the eddy current density and induced power density in the billet. Finally, the temperature profile inside the billet is obtained with two dimensional finite elements software (COMSOL).

\section{DESCRIPTION OF THE INDUCTION HEATER}

Fig. 1 shows the cross section of the studied induction heater. It is composed of an inductor made from superconducting coils which create a strong DC magnetic field. The aluminium billet to be heated is placed inside the warm hole of the cryostat and moves linearly at a low speed. The linear displacement of the billet in the DC magnetic field generates induced currents which produce a Joule heating in it. As will be shown in the paper, the use of a low linear speed and a strong DC magnetic field allow obtaining a large skin depth and therefore a homogeneous temperature distribution inside the billet, which is necessary before the press-forming step. The physical parameters of the studied device are given in Table I. The geometrical parameters have been chosen arbitrarily in order to test the analytical model developed in the paper. 
TABLE I

PHYSICAL AND GEOMETRICAL PARAMETERS OF THE STUDIED INDUCTION HEATER

\begin{tabular}{lll}
\hline \hline \multirow{2}{*}{ Symbol } & \multicolumn{1}{c}{ Quantity } & \multicolumn{1}{c}{ Value } \\
\hline$R_{1}$ & Billet radius & $8 \mathrm{~cm}$ \\
$R_{2}$ & Superconducting coil inner radius & $13 \mathrm{~cm}$ \\
$e$ & Superconducting coil thickness & $4 \mathrm{~cm}$ \\
$a$ & Width of the coil & $15 \mathrm{~cm}$ \\
$b$ & Distance between two coils & $10 \mathrm{~cm}$ \\
$L$ & Billet axial length & $1 \mathrm{~m}$ \\
$V$ & Linear velocity of the billet & variable \\
$\sigma$ & Electrical conductivity of the billet $(\mathrm{Al})$ & $3710^{6} \Omega^{-1} \mathrm{~m}^{-1}$ \\
$\mu_{0}$ & Magnetic permeability & $4 \pi 10^{-7} \mathrm{H}^{-1}$ \\
$\lambda_{t}$ & Thermal conductivity of the billet & $206 \mathrm{Wm}^{-1} \mathrm{~K}^{-1}$ \\
$\rho$ & Specific mass of aluminium & $2707 \mathrm{Kg} \mathrm{m}^{-3}$ \\
$c$ & Specific heat of aluminium & $936 \mathrm{~J} \mathrm{Kg}^{-1} \mathrm{~K}^{-1}$ \\
$J$ & Current density in the superconducting & $200 \mathrm{~A} / \mathrm{mm}^{2}$ \\
& coils & \\
\hline \hline
\end{tabular}

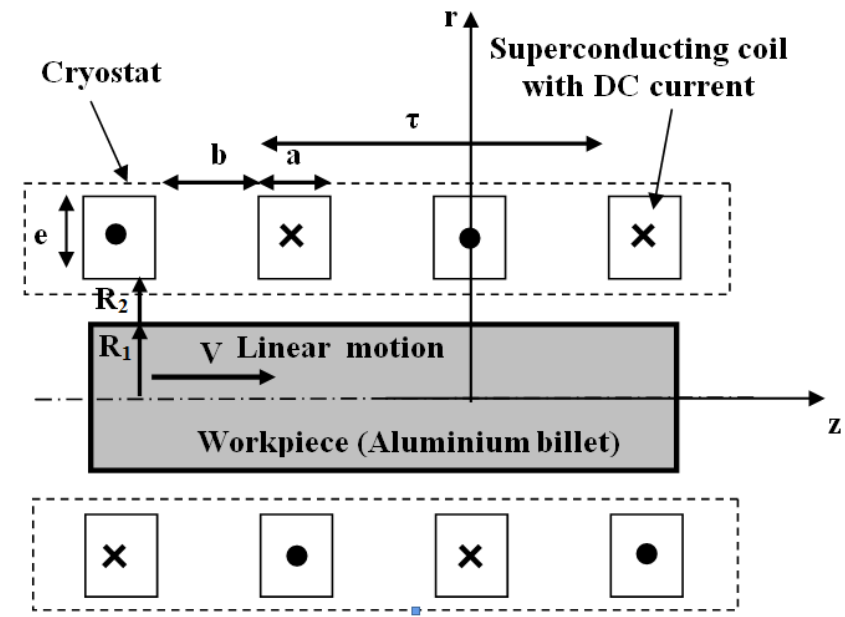

Fig.1. Induction heater with DC magnetic field and linear motion

\section{EQUIVALENT CURRENT SHEET}

To reduce the study to a $2 \mathrm{D}$ axisymmetric problem, we consider that the induction heater (the inductor and the billet) has an infinite axial length. The billet is subjected to a linear movement along the $z$ axis with a constant velocity $V$. In the analysis, the current in the superconducting coil is replaced by a current sheet of radius $R_{2}+e / 2$ with an infinite axial length as shown in Fig. 2 [12]-[13]. This current sheet is chosen to carry the same current as the original coil.

The superconducting winding is excited with a DC current density $J$. The electrical current in a coil is given by

$$
I=a e J
$$

The corresponding value of the equivalent current sheet in $\mathrm{A} / \mathrm{m}$ is then

$$
J_{s}=e J
$$

where $J$ and $J_{S}$ have only one component in the $\theta$ direction.

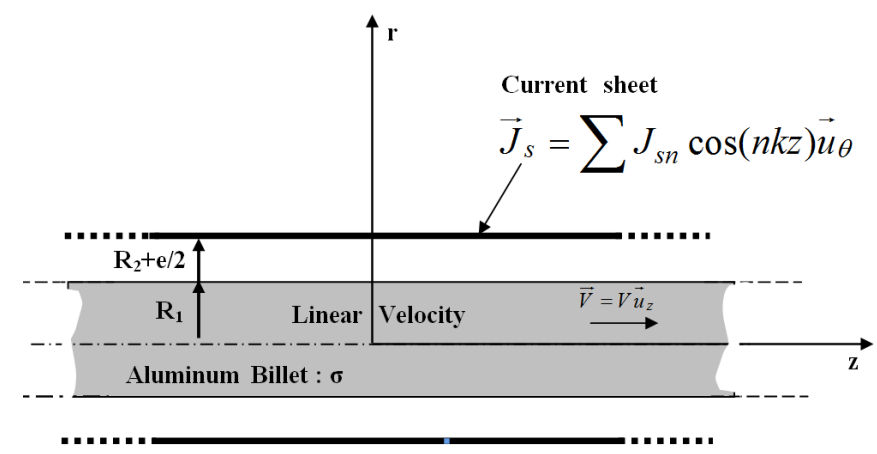

Fig.2. Simplified model used for the analysis

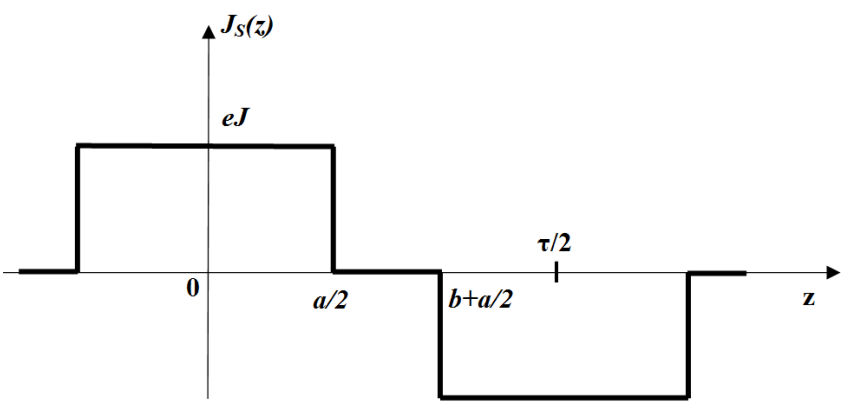

Fig.3. Current sheet distribution along the axial coordinate $z$

The current sheet distribution versus the coordinate $z$ is shown in Fig. 3. Its Fourier series expansion is

$$
J_{s}(z)=\sum_{n} J_{s n} \cos (n k z) \quad \text { with } \quad k=\frac{2 \pi}{\tau}
$$

where $J_{s n}$ is the peak value of the $n t h$ harmonic component of the current sheet given by

$$
J_{s n}=\frac{4 e J}{n \pi} \sin \left(\frac{n \pi a}{\tau}\right)
$$

with $\tau=2(a+b)$ the spatial period of the current sheet.

Due to the cryostat and thermal insulation thicknesses, the radius of the billet is relatively small compared to the inner radius of the superconducting coil. Hence, the higher harmonic terms of the flux density strongly decrease with the air gap thickness. In this study, only the fundamental term $(n=1)$ of the current sheet distribution is considered.

$$
J_{s 1}(z)=\frac{4 e J}{\pi} \sin \left(\frac{\pi a}{\tau}\right) \cos (k z)
$$

\section{MATHEMATICAL FORMULATION}

A general multiregion problem is analyzed. The whole space is divided into three regions as shown in Fig. 4.

- Region 1 corresponds to the conducting billet (workpiece). - Region 2 corresponds to the space between the billet and the current sheet.

- Region 3 corresponds to the space outside the current sheet. 


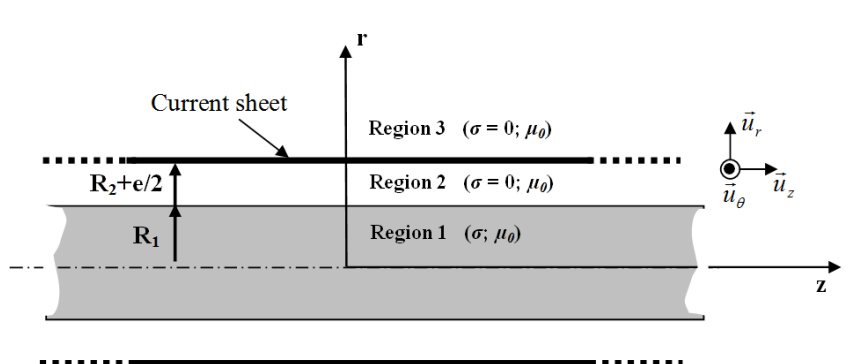

Fig.4. Multiregion problem used for the analysis

\section{A. Diffusion equation}

By considering the movement of the billet, the electromagnetic behaviour of the system is described by Maxwell's equations expressed as

$$
\begin{array}{ll}
\vec{\nabla} \times \vec{H}=\vec{J} & \vec{\nabla} \times \vec{E}=-\frac{\partial \vec{B}}{\partial t} \\
\vec{\nabla} \cdot \vec{B}=0 & \vec{\nabla} \cdot \vec{E}=0
\end{array}
$$

with the material properties

$$
\begin{aligned}
& \vec{J}=\sigma(\vec{V} \times \vec{B}) \quad \text { with } \vec{V}=V \vec{u}_{z} \\
& \vec{B}=\mu_{0} \vec{H}
\end{aligned}
$$

The magnetic vector potential $\vec{A}$ is defined by

$$
\vec{B}=\vec{\nabla} \times \vec{A}
$$

The combination of (6), (7) and (8) gives the magnetic diffusion equation which takes into account the movement of the conducting billet

$$
\begin{cases}\vec{\nabla} \times \vec{\nabla} \times \vec{A}=\sigma \mu_{0}(\vec{V} \times \vec{\nabla} \times \vec{A}) & \text { in region } 1 \\ \vec{\nabla} \times \vec{\nabla} \times \vec{A}=0 & \text { in regions } 2 \text { and } 3\end{cases}
$$

Due to the axial symmetry, the studied problem is invariant according to the $\theta$-coordinate. So, the electric and magnetic quantities will be independent of $\theta$. Under these conditions, the magnetic vector potential, in each region, presents only one component in the azimuthal direction, and depends only on $r$ and $z$ variables. Then, (9) becomes in region 1

$$
\frac{\partial^{2} A_{1}}{\partial r^{2}}+\frac{1}{r} \frac{\partial A_{1}}{\partial r}-\frac{1}{r^{2}} A_{1}+\frac{\partial^{2} A_{1}}{\partial z^{2}}=\sigma \mu_{0} V \frac{\partial A_{1}}{\partial z}
$$

\section{B. Magnetic vector potential expressions}

According to the form of the current sheet excitation for the fundamental term of the Fourier series (5), the solution of the magnetic vector potential in region $i(i=1,2,3)$ can be written as

$$
A_{i}(r, z)=A_{i}(r) \cos \left(k z+\varphi_{i}(r)\right)
$$

Since the magnetic vector potential is varying sinusoidally in space, we can use the complex notation

$$
A_{i}(r, z)=\mathfrak{R}\left\{\bar{A}_{i}(r) e^{j k z}\right\}
$$

Where $\mathfrak{R}$ denotes the real part of a complex number. Using the complex representation, (10) becomes a modified Bessel differential equation

$$
r^{2} \frac{d^{2} \bar{A}_{1}}{d r^{2}}+r \frac{d \bar{A}_{1}}{d r}-\left(\lambda^{2} r^{2}+1\right) \bar{A}_{1}=0
$$

with

$$
\lambda^{2}=k^{2}+j k \sigma \mu_{0} V \text { and } j=\sqrt{-1}
$$

In the conducting billet (Region 1), the general solution of (13), knowing that $\bar{A}_{1}$ must be finite when $r \rightarrow 0$, has the following form [14]

$$
\bar{A}_{1}(r)=a_{1} I_{1}(\lambda r)
$$

where $I_{l}$ is the modified Bessel function of the first kind and order 1 and $a_{l}$ is a complex coefficient which will be determinate using the interface conditions.

For region 2 where the electrical conductivity $\sigma=0$, the general solution is

$$
\bar{A}_{2}(r)=a_{2} I_{1}(k r)+b_{2} K_{1}(k r)
$$

where $K_{1}$ is the modified Bessel function of the second kind and order 1.

For region 3 , knowing that $\bar{A}_{3}$ must be finite when $r \rightarrow \infty$, the solution is

$$
\bar{A}_{3}(r)=b_{3} K_{1}(k r)
$$

The complex coefficients $a_{1}, a_{2}, b_{2}$ and $b_{3}$ in (15), (16) and (17) are determined using the interface conditions between the different regions

$$
\text { at } r=R_{1}: \quad\left\{\begin{array}{l}
\bar{A}_{1}=\bar{A}_{2} \\
\frac{d \bar{A}_{1}}{d r}=\frac{d \bar{A}_{2}}{d r}
\end{array}\right.
$$

at $r=R_{2}+\frac{e}{2}$ (current sheet interface):

$$
\left\{\begin{array}{l}
\bar{A}_{2}=\bar{A}_{3} \\
\frac{d \bar{A}_{2}}{d r}=\frac{d \bar{A}_{3}}{d r}+\mu_{0} J_{s 1}
\end{array}\right.
$$


We obtain a system of four linear equations from which we extract the expressions of the coefficients $a_{1}, a_{2}, b_{2}$ and $b_{3}$. The magnetic vector potential in region 1 is then expressed as

$$
\bar{A}_{1}(r)=\frac{\mu_{0} J_{s 1}}{k C}\left[\frac{I_{1}\left(k R_{1}\right)}{I_{1}\left(\lambda R_{1}\right)}+\frac{1}{D} \frac{K_{1}\left(k R_{1}\right)}{I_{1}\left(\lambda R_{1}\right)}\right] I_{1}(\lambda r)
$$

with

$$
C=I_{0}\left(k\left(R_{2}+\frac{e}{2}\right)\right)+\left[\frac{K_{0}\left(k\left(R_{2}+\frac{e}{2}\right)\right) I_{1}\left(k\left(R_{2}+\frac{e}{2}\right)\right)}{K_{1}\left(k\left(R_{2}+\frac{e}{2}\right)\right)}\right]
$$

and

$$
D=\frac{k I_{1}\left(\lambda R_{1}\right) K_{0}\left(k R_{1}\right)+\lambda K_{1}\left(k R_{1}\right) I_{0}\left(\lambda R_{1}\right)}{k I_{0}\left(k R_{1}\right) I_{1}\left(\lambda R_{1}\right)-\lambda I_{1}\left(k R_{1}\right) I_{0}\left(\lambda R_{1}\right)}
$$

where $I_{0}$ and $K_{0}$ are respectively the modified Bessel function of the first kind and the second kind, of order 0 .

\section{Eddy current expression}

The induced current density in the aluminium billet (region 1) can be obtained from the following relation

$$
\vec{J}_{1}(r, z)=\sigma\left(\vec{V} \times \vec{\nabla} \times \vec{A}_{1}\right)=-\sigma V \frac{\partial \vec{A}_{1}(r, z)}{\partial z}
$$

which becomes in the complex domain

$$
\bar{J}_{1}(r)=-j \sigma V k \bar{A}_{1}(r)
$$

Finally, the expression of the induced current density can be written as

$$
J_{1}(r, z)=\Re\left\{\bar{J}_{1}(r) e^{j k z}\right\}
$$

\section{Induced heating power expression}

The induced power density in the billet is expressed as:

$$
p(r, z)=\frac{J_{1}^{2}(r, z)}{\sigma}
$$

So the induced power in the billet of length $\mathrm{L}$ is

$$
P=\int_{0}^{R_{1}} \int_{0}^{2 \pi} \int_{-L / 2}^{L / 2} \frac{J_{1}^{2}(r, z)}{\sigma} r d r d \theta d z
$$

Substituting (20) and (24) into (25) and then (25) into (27), we obtain the analytical expression of the induced heating power in the conducting billet

$$
P=2 \pi \sigma V^{2} k^{2} a_{1} a_{1}^{*} \cdot E \cdot F
$$

where

$$
a_{1}=\frac{\mu_{0} J_{s 1}}{k C}\left[\frac{I_{1}\left(k R_{1}\right)}{I_{1}\left(\lambda R_{1}\right)}+\frac{1}{D} \frac{K_{1}\left(k R_{1}\right)}{I_{1}\left(\lambda R_{1}\right)}\right]
$$

and

$$
\begin{aligned}
& E=\frac{R_{1}}{\lambda-\lambda^{*}}\left[\lambda I_{0}\left(\lambda R_{1}\right) I_{1}\left(\lambda^{*} R_{1}\right)-\lambda^{*} I_{0}\left(\lambda^{*} R_{1}\right) I_{1}\left(\lambda R_{1}\right)\right](30) \\
& F=\frac{1}{2}\left(L+\frac{\sin (k L) \cos \left(2 \varphi_{1}\left(R_{1}\right)\right)}{k}\right)
\end{aligned}
$$

where $\varphi_{1}\left(R_{1}\right)$ is the argument of $\bar{A}_{1}\left(R_{1}\right)$ given by (20).

The analytical expression of the induced heating power in the billet (28) depends on the geometrical and physical parameters of the induction heater. This expression will be used in the next section to study the effect of the geometrical parameters on the performance of the induction heater.

\section{RESULTS AND DISCUSSION}

\section{A. Eddy current density}

Figs. 5 and 6 show the flux lines and the magnetic flux density distribution obtained by finite element method (COMSOL) when the conducting billet is moving respectively at a linear velocity of $V=0.24 \mathrm{~m} / \mathrm{s}$ and $V=0.62 \mathrm{~m} / \mathrm{s}$. The superconducting coil is excited with a current density $J=200$ $\mathrm{A} / \mathrm{mm}^{2}$. One can observe that the flux lines are driven in the direction of the motion and are rejected from the billet when the speed increases.

The critical current in the superconducting coil is closely dependent on the maximum value of the flux density. Hence, it is important in the design of the HTS induction heater to carefully consider this maximum value. In the case of the simulations of Figs.5 and 6, a maximum value of around 5T appears in the inner surface of the coils. Notice that this value is acceptable for DI-BSCCO HTS tapes [15] for which the critical current density is higher than $200 \mathrm{~A} / \mathrm{mm}^{2}$ for operating temperatures of $15-20 \mathrm{~K}$.

Fig. 7 and 8 show the spatial distribution of the eddy currents in the billet for $V=0.24 \mathrm{~m} / \mathrm{s}$ and $V=0.62 \mathrm{~m} / \mathrm{s}$.

The eddy current density versus the radial distance $r$ at $z=0$ for a linear speed of $V=0.24 \mathrm{~m} / \mathrm{s}$ and $V=0.62 \mathrm{~m} / \mathrm{s}$ are given respectively in Figs. 9 and 10. We can notice that the results obtained with the analytical method (current sheet approximation with the first harmonic) are in good agreement with those obtained by FEM (the real coil geometry is considered in the FE computations). 


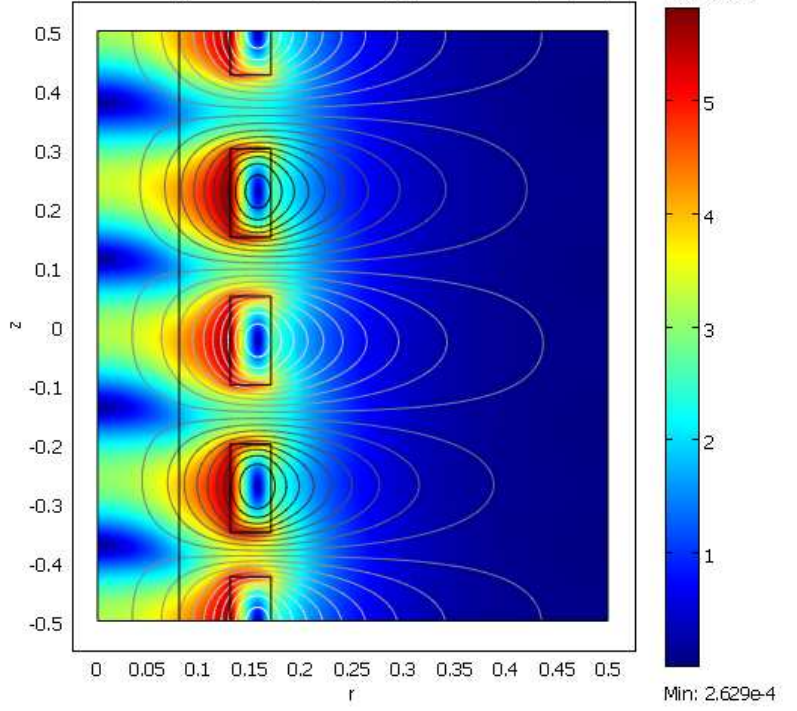

Fig.5. Flux lines distribution and magnetic flux density distribution (T) for $V$ $=0.24 \mathrm{~m} / \mathrm{s}$ and $J=200 \mathrm{~A} / \mathrm{mm}^{2}$

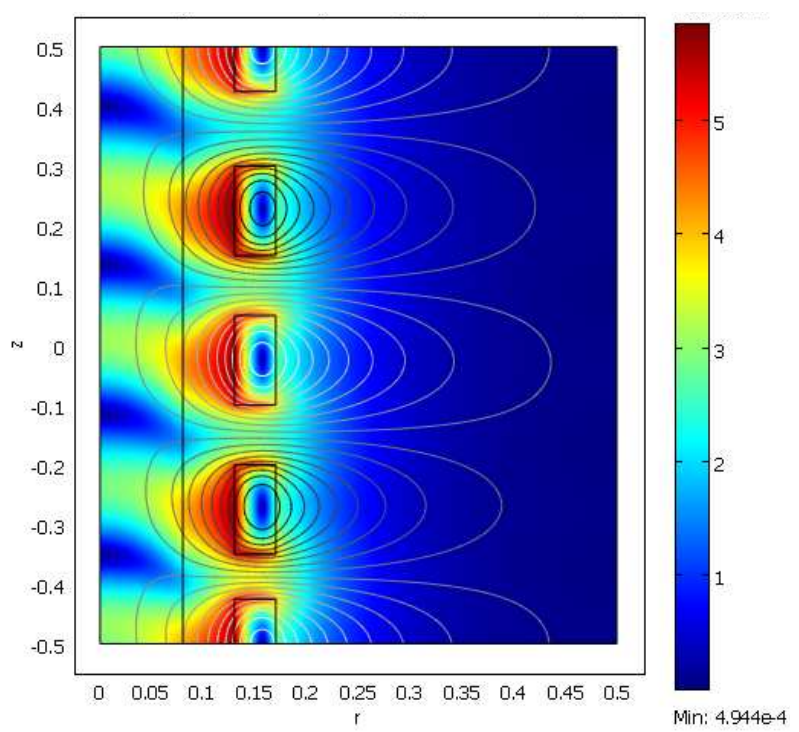

Fig.6. Flux lines distribution and magnetic flux density distribution (T) for $V$ $=0.62 \mathrm{~m} / \mathrm{s}$ and $J=200 \mathrm{~A} / \mathrm{mm}^{2}$

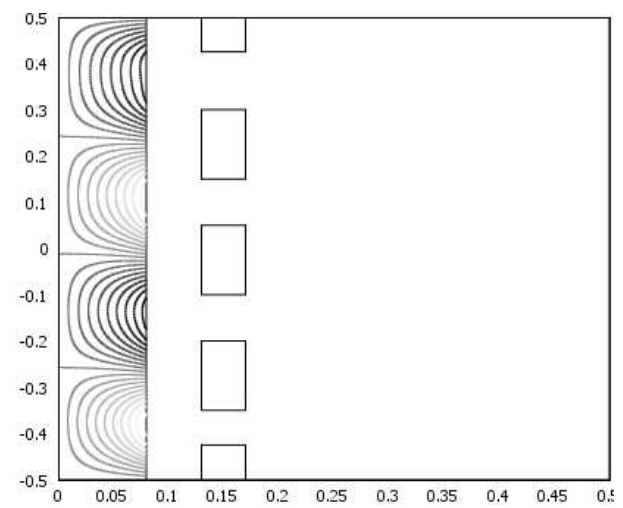

Fig.7. Eddy current distribution in the billet for $V=0.24 \mathrm{~m} / \mathrm{s}$ and $J=200$ $\mathrm{A} / \mathrm{mm}^{2}$

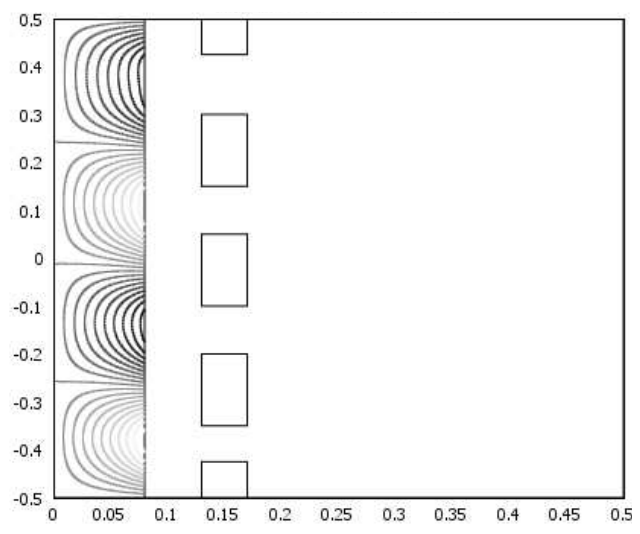

Fig.8. Eddy current distribution in the billet for $V=0.62 \mathrm{~m} / \mathrm{s}$ and $J=200$ $\mathrm{A} / \mathrm{mm}^{2}$.

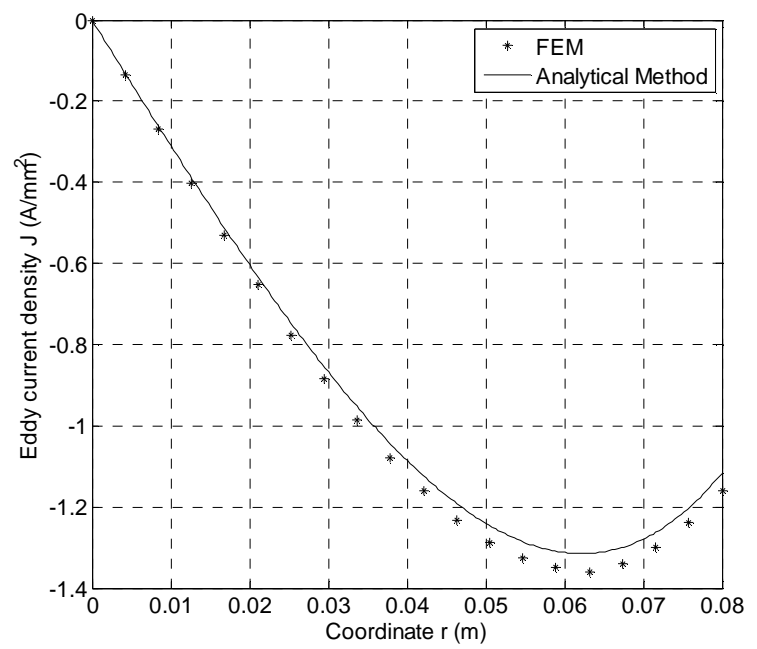

Fig.9. Eddy current density versus the radial distance $r$ (at $z=0$ ) for $V=0.24 \mathrm{~m} / \mathrm{s}$ and $J=200 \mathrm{~A} / \mathrm{mm}^{2}$

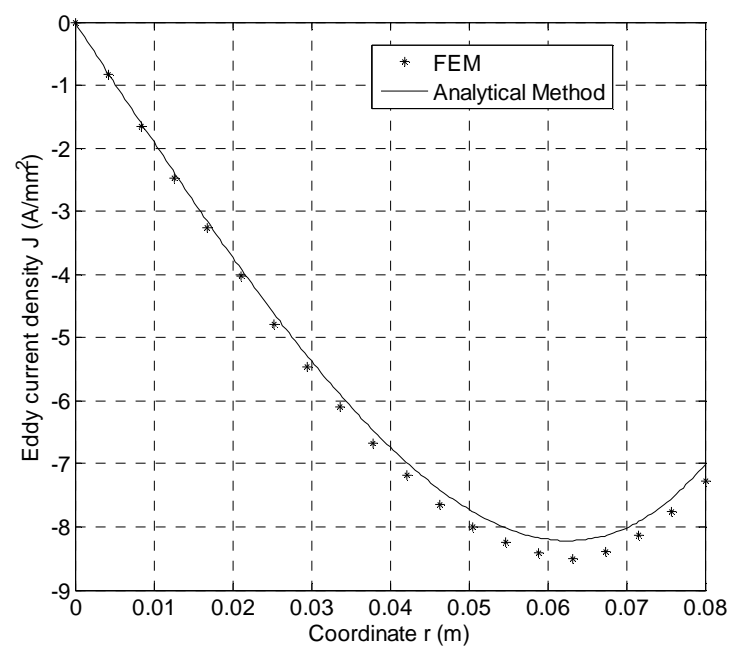

Fig.10. Eddy current density versus the radial distance $r$ (at $z=0$ ) for $V=0.62 \mathrm{~m} / \mathrm{s}$ and $\mathrm{J}=200 \mathrm{~A} / \mathrm{mm}^{2}$

Figs. 11 and 12 show the eddy current density versus the axial distance $z$ at the surface of the billet $\left(r=R_{1}\right)$ for $V=0.24$ $\mathrm{m} / \mathrm{s}$ and $V=0.62 \mathrm{~m} / \mathrm{s}$. Obviously, the eddy current density presents a sinusoidal variation along the $\mathrm{z}$-axis. 


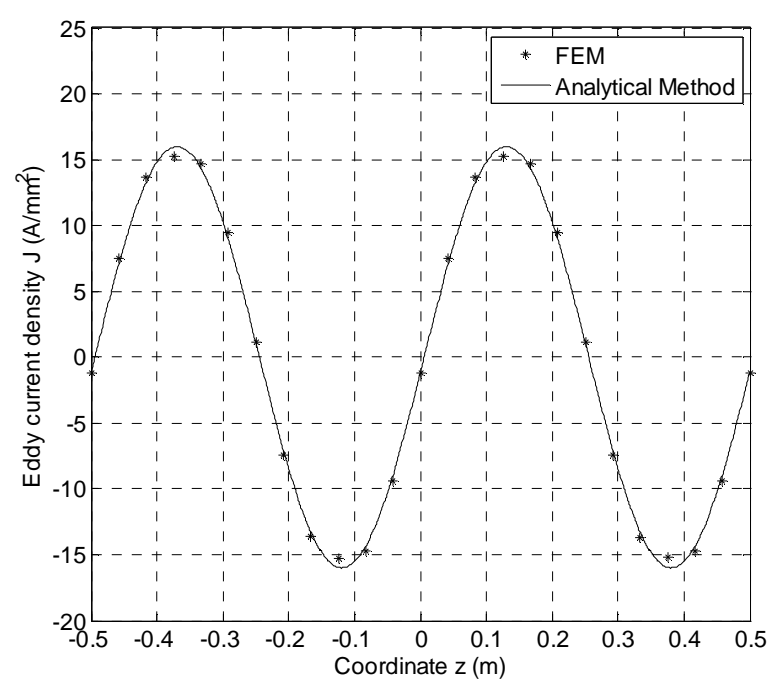

Fig.11. Eddy current density versus the axial distance $z\left(\right.$ at $\left.r=R_{l}\right)$ for $V=0.24 \mathrm{~m} / \mathrm{s}$ and $J=200 \mathrm{~A} / \mathrm{mm}^{2}$

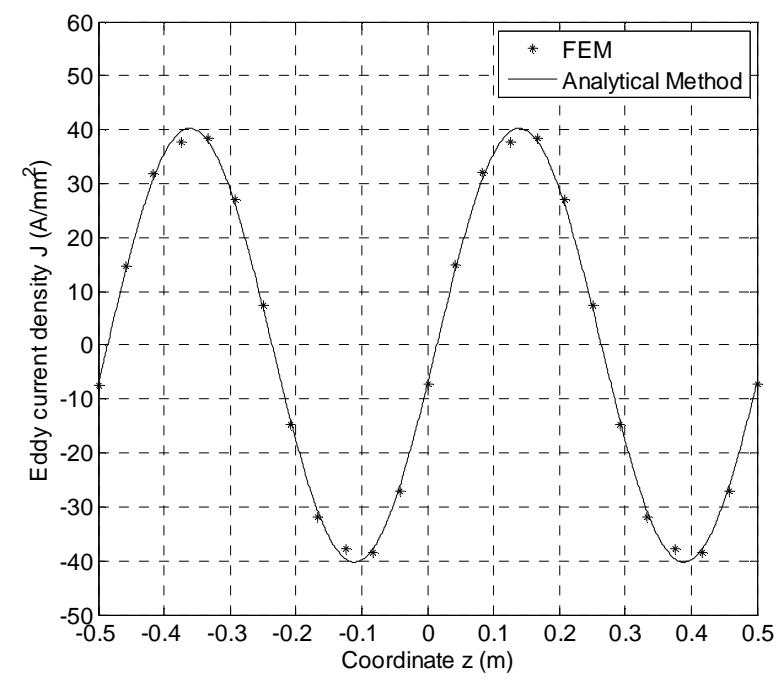

Fig. 12. Eddy current density versus the axial distance $z$ (at $r=R_{1}$ ) for $V=0.62 \mathrm{~m} / \mathrm{s}$ and $J=200 \mathrm{~A} / \mathrm{mm}^{2}$

\section{B. Induced heating power}

The power density variation with respect to radius is plotted in Fig. 13 for two values of the velocity. As for the current density (Figs. 9, 10), the penetration of the power density is higher in the case of low velocity values.

The induced heating power in the conducting billet obtained for various values of the linear velocity $V$ and for the coil excited by a DC current density $J=200 \mathrm{~A} / \mathrm{mm}^{2}$ is given in Fig. 14. These results have been obtained using the analytical expression (28) and compared with those obtained by FEM (FEM with real coil distribution). We can observe that the analytical model can predict with a very good precision the induced power in the billet. Furthermore, the analytical computations are much faster than the numerical ones. Therefore it could be used as an efficient tool to study the influence of the geometrical parameters on the induced heating power.

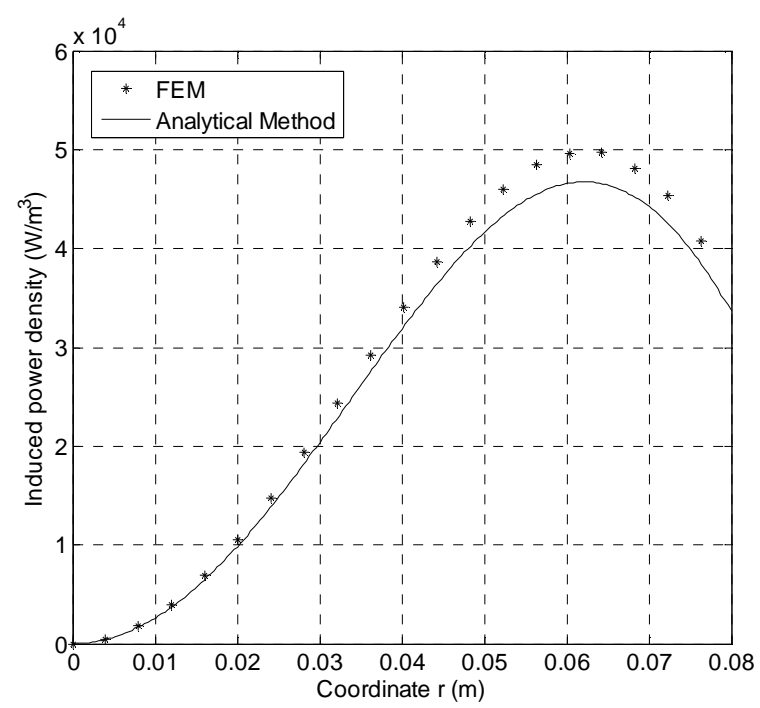

(a)

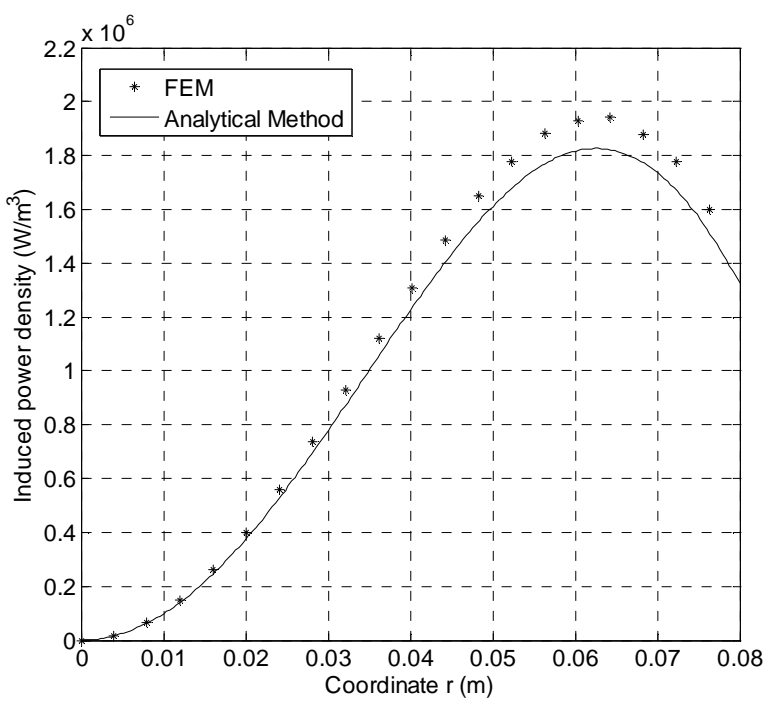

(b)

Fig.13. Induced power density versus the radius $r$ at $z=0$ a) $V=0.24 \mathrm{~m} / \mathrm{s}$ b) $V=0.62 \mathrm{~m} / \mathrm{s}$

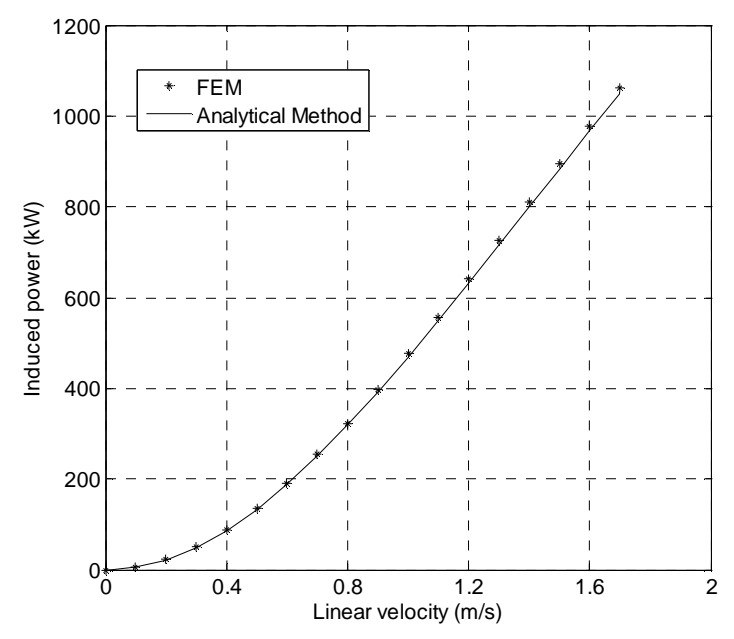

Fig.14. Induced heating power versus the linear velocity for $J=200 \mathrm{~A} / \mathrm{mm}^{2}$ 


\section{Design analysis of the induction heater}

1) Effect of the distance between two coils (parameter b)

Using the analytical expression (28), Figs. 15 and 16 show the effect of the distance between two superconducting coils (inductor) on the induced power for two values of the linear velocity $V$. We can observe that the induced power presents a maximum value for $b=7.5 \mathrm{~cm}$, then decreases while increasing the distance $b$.

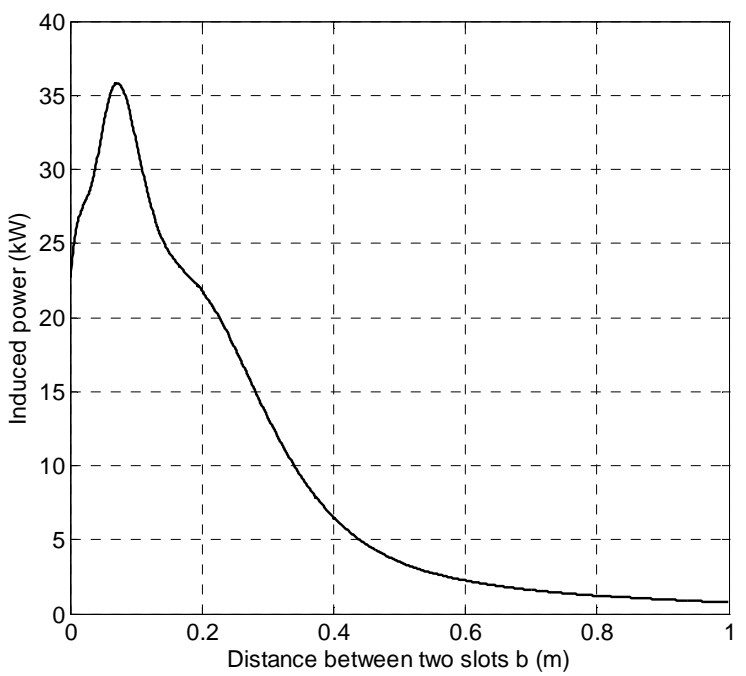

Fig.15. Induced heating power versus the distance between two superconducting coils for $V=0.24 \mathrm{~m} / \mathrm{s}$ and $J=200 \mathrm{~A} / \mathrm{mm}^{2}$

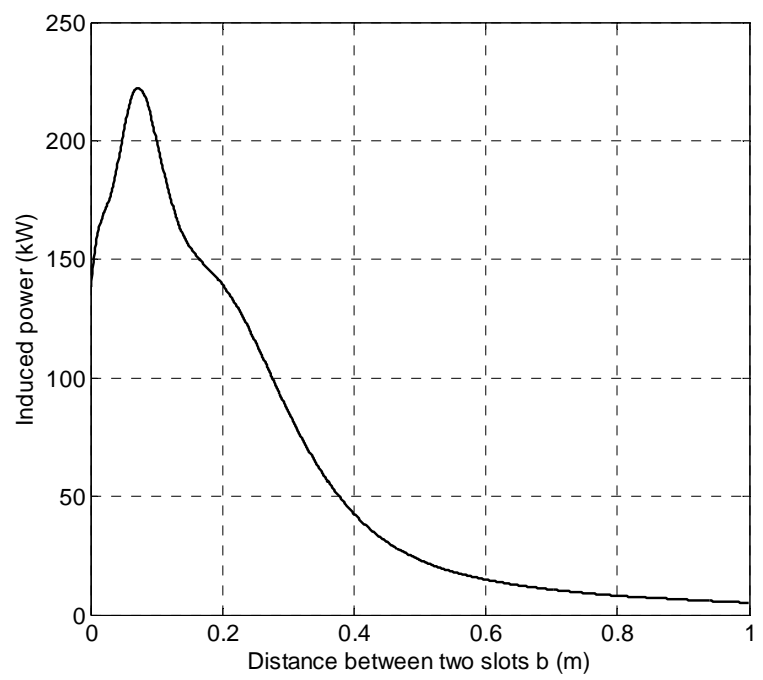

Fig.16. Induced heating power versus the distance between two superconducting coils for $V=0.62 \mathrm{~m} / \mathrm{s}$ and $J=200 \mathrm{~A} / \mathrm{mm}^{2}$

\section{2) Effect of the distance between the inductor and the conducting billet}

Figs. 17 and 18 show the effect of the ratio $\left(R_{2}+e / 2\right) / R_{1}$ on the induced power for various values of the linear velocity $V$. A certain distance is necessary between the inductor and the billet. Indeed, the superconducting coils must be placed inside the cryostat and a thermal insulation must be placed between the cryostat and the billet. As expected, one can observe on
Figs. 17 and 18 that the induced power decreases rapidly when the distance between the inductor and the conducting billet increases.

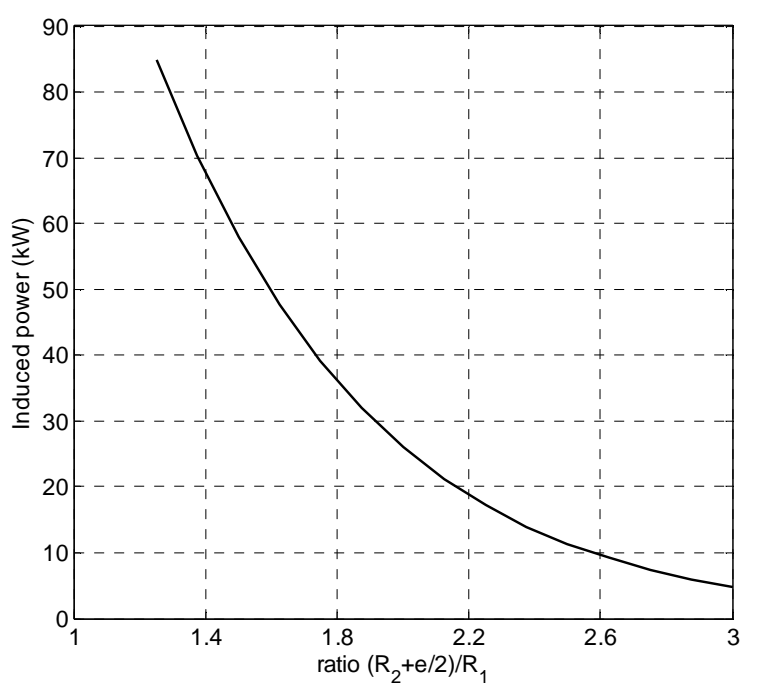

Fig. 17. Induced power versus the distance between the inductor and the billet for $V=0.24 \mathrm{~m} / \mathrm{s}$ and $J=200 \mathrm{~A} / \mathrm{mm}^{2}$

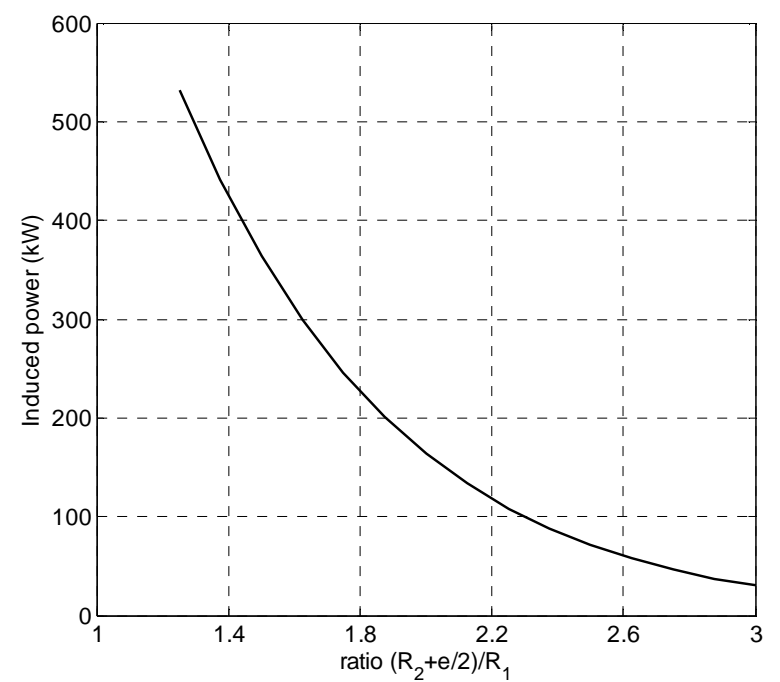

Fig.18. Eddy current versus the distance between the inductor and the billet for $V=0.62 \mathrm{~m} / \mathrm{s}$ and $J=200 \mathrm{~A} / \mathrm{mm}^{2}$

\section{TEMPERATURE FIELD ANALYSIS}

Taking into account the movement of the conducting billet, the equation describing the heat transfer phenomenon in the billet to be heated is given by [9],[16]

$$
\rho c\left(\frac{\partial T}{\partial t}+\vec{V} \cdot \vec{\nabla} T\right)=p(r, z)+\lambda_{t} \Delta T
$$

where $T, \lambda_{t}, \rho$ and $c$ respectively represent the temperature, the thermal conductivity of the billet, the specific mass and the specific heat. The term $\vec{V} \cdot \vec{\nabla} T$ in (32) is the convective term 
due to the motion of the billet and $p(r, z)$ is the heat source produced by eddy current in the billet. In 2D cylindrical coordinates, the boundary value problem describing the temperature evolution is defined only in region 1 (adiabatic condition is considered on the surface of the billet)

$$
\begin{gathered}
\rho c\left(\frac{\partial T}{\partial t}+V \frac{\partial T}{\partial z}\right)=p(r, z)+\lambda_{t}\left(\frac{\partial^{2} T}{\partial r^{2}}+\frac{1}{r} \frac{\partial T}{\partial r}+\frac{\partial^{2} T}{\partial z^{2}}\right) \\
\left.\frac{\partial T}{\partial r}\right|_{r=R_{1}}=0 \\
T(r, z, t=0)=30^{\circ} \mathrm{C}
\end{gathered}
$$

The problem is solved with 2D finite element software (COMSOL). The induced power density is evaluated using the electromagnetic problem with a constant linear velocity $V$ of the billet. The source term for the heat transfer problem is the one given by (26).

Fig. 19 gives the transient temperature profile at the centre of the conducting billet. The linear velocity of the billet is constant and equal to $V=0.62 \mathrm{~m} / \mathrm{s}$ and the current density in the superconducting coil is fixed at $J=200 \mathrm{~A} / \mathrm{mm}^{2}$. The corresponding induced heating power in the billet is about 200 $\mathrm{kW}$. We observe that the temperature inside the billet increases almost linearly because the boundary condition on the surface of the billet is adiabatic. The rise time to heat the conducting billet from $30{ }^{\circ} \mathrm{C}$ to $500{ }^{\circ} \mathrm{C}$ is about $145 \mathrm{~s}$.

Fig 20 shows the temperature distribution inside the conducting billet along the radial distance $r$ at $t=150 \mathrm{~s}$.

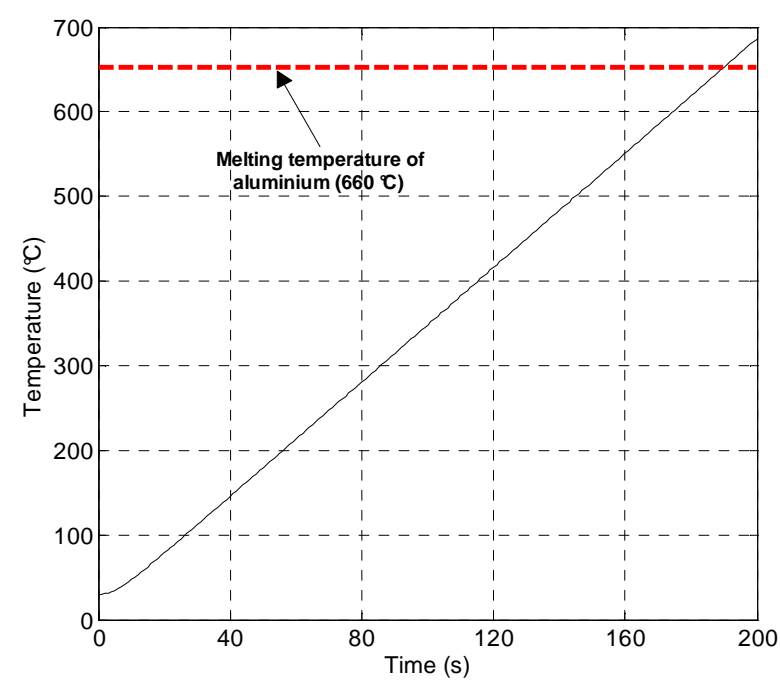

Fig. 19: Transient temperature profile at the center of the billet for $V=0.62 \mathrm{~m} / \mathrm{s}$ and $J=200 \mathrm{~A} / \mathrm{mm}^{2}$

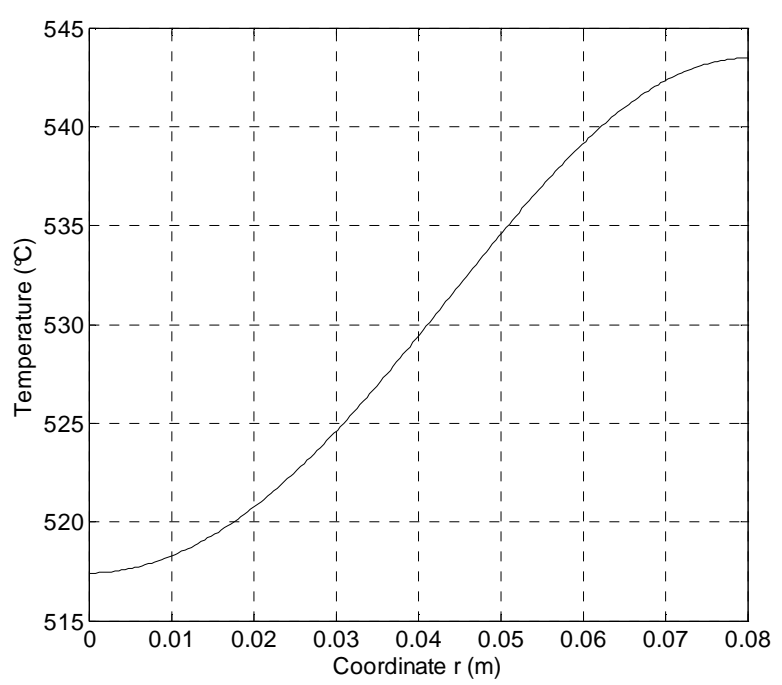

Fig.20: Temperature distribution in the billet versus the radial distance $r$ for $V=0.62 \mathrm{~m} / \mathrm{s}$ and $J=200 \mathrm{~A} / \mathrm{mm}^{2}$ at time $t=150 \mathrm{~s}$.

The maximum temperature is $T=543^{\circ} \mathrm{C}$ on the surface of the conducting billet and the minimum one is $T=517^{\circ} \mathrm{C}$ at the centre of the billet. This result shows that the temperature is sufficiently homogeneous in the billet (within 5\%), which is suitable for press forming operation.

It is important to keep in mind that the analysis developed in the paper is a simplification of a 3-D problem to a 2-D one. Indeed, we have supposed an infinitely long cylinder whereas the length of the cylinder is finite. The end effect is ignored so the power density in the end regions of the cylinder will be smaller than in the centre of the billet. This can be shown only with a $3 \mathrm{D}$ analysis.

\section{CONCLUSION}

In this paper, we have presented a new structure of induction heaters for aluminium billets. The device consists in using a strong DC magnetic field created by a superconducting inductor in which the conducting billet is actuated by a linear movement at a constant velocity.

An analytical model for the magnetic field distribution in the billet has been developed, and then the eddy currents and the induced heating power have been evaluated. The results obtained using this model are validated through finite element computations. The analytical model has been used to study the effect of the geometrical parameters on the performance of the induction heater. It has been shown that an optimum distance exists between the superconducting coils to obtain the maximum induced power in the billet. By solving the thermal problem, we have also shown that the heat power is distributed in the heart of the billet, so the temperature is sufficiently homogeneous in the billet and satisfies the requirement for press forming operation. 
The considered model being a $2 \mathrm{D}$ one, it will probably be necessary to develop a full 3D model in order to consider the end effects. Furthermore, the choice of a constant velocity leads to a very long furnace which may be a limitation for this heating system. The use of an oscillating system would probably be more suitable. Finally, it will be important to consider the end effects as well as the reaction field since they affect the performances of the superconducting coils (losses and critical current density).

\section{REFERENCES}

[1] V. Rudnev, D. Loveless, R. Cook, and M. Black, Handbook of Induction Heating. New York: Marcel Dekker, 2003.

[2] M. Runde, and N. Magnusson, "Induction heating of aluminium billets using superconducting coils," Physica C, vol. 372-376, pp. 1339-1341, Aug. 2002.

[3] M. Runde, and N.Magnusson, "Design, building and testing of a $10 \mathrm{~kW}$ superconducting induction heater," IEEE Trans. Appl. Supercond., vol.13, no. 2, pp.1612-1615, Jun. 2003.

[4] N. Magnusson, and M. Runde, "Efficiency analysis of a hightemperature superconducting induction heater," IEEE Trans. Appl. Supercond., vol. 13, no. 2, pp. 1616-1619, Jun. 2003.

[5] N. Magnusson, and M. Runde, "A $200 \mathrm{~kW} \mathrm{MgB2}$ induction heater project," J. Phys.: Conf. Ser., 2006, vol. 43, pp. 1019-1022.

[6] I. Hiltunen, A. Stenvall, A. Korpela, J. Lehtonen, R. Mikkonen, M Runde, N. Magnusson, and G. Kalkowski, "Cryogenic design of the Aluheat project, " Trans. Cryogenic Engineering Conf., vol. 985, pp. 1015-1022, 2008

[7] M. Runde, N. Magnusson, C. Fulbier, and C. Buhrer, "Commercial induction heaters with high temperature superconductor coils," IEEE Trans. Appl. Supercond, to be published, 2011.

[8] M. Fabbri, A. M. Forzan, S. Lupi, A. Morandi, and P. L. Ribani, "Experimental and numerical analysis of DC induction heating of aluminium billets," IEEE Trans. Magn., vol. 45, no. 1, pp. 192-200 Jan. 2009.

[9] T. Lubin, D. Netter, J. Leveque, and A. Rezzoug, "Induction heating of aluminium billet subjected to a strong rotating magnetic field produced by superconducting windings," IEEE Trans. on Magn., vol. 45, no 5, pp. 2118-2127, May 2009.

[10] N. Magnusson, "An apparatus and a method for induction heating of pieces of electrically conducting and non-magnetic material," Norwegian Patent $\mathrm{N}^{\circ}$ WO2004066681, Aug. 5, 2004.

[11] J. Müller, J. Wiezoreck, and C. Bührer, "Energy efficient metal heating installation," German Patent N ${ }^{\circ}$ WO2005109955, Nov. 17, 2005.

[12] N. Esposito, M. Raugi, and A. Tellini, " Quasi analytical model for eddy currents and force in axisymmetric geometries with moving conductors," IEEE Trans. Magn., vol. 29, no. 6, pp. 2407-2409, Nov. 1993.

[13] J. L. He, E. Levi, and Z. Zabar, "Analysis of induction type coilgun performance based on cylindrical current sheet model," IEEE Trans. Magn., vol. 27, no.1, pp. 579-584, Jan. 1991.

[14] M. Abramowitz and I. Stegun, Handbook of Mathematical Function. New York: Dover, 1972.

[15] Sumitomo Electric, Superconductivity. Internet: http://globalsei.com/super/hts e/type h.html.

[16] S. L. Ho, Junhua Wang, and Y. H. Wang, "A novel crossed traveling wave induction heating system and finite element analysis of eddy current and temperature distributions," IEEE Trans. Magn., vol. 45, no.10, pp. 4777-4780, Oct. 2009.
Hakim Bensaidane was born in Tizi-ouzou, Algeria, in 1977. He received the engineer diploma and the magister degree from the university Mouloud Mammeri, Tizi-ouzou, Algeria in 2003 and 2006 respectively.

He is currently Ph.D. student at the University of Sciences and Technology Houari Boumediene, Algiers, Algeria, at the laboratoire des systems électriques et industriels de l'USTHB d'Alger where his research interests include modeling and electromagnetic computation of electromechanical devices and power electric system.

Youcef Ouazir was born in Setif, Algeria, in 1970. He received the engineer diploma,the magister and Ph.D degree from the Ecole Nationale Polytechnique d'Algier, Algeria in 1994, 1997 and 2006 respectively.

$\mathrm{He}$ is currently a lecturer at the University of Sciences and Technology Houari Boumediene (USTHB), Algiers, and a member of the laboratoire des systems électriques et industriels. His research interests include the modeling and electromagnetic computation of electromechanical devices and power electric system.

Thierry Lubin was born in Sedan, France, in 1970. He received the M.S. degree from the University of Paris 6, France in 1994 and the Ph.D. degree from the University Henri Poincaré, Nancy, France, in 2003.

$\mathrm{He}$ is currently a lecturer of Electrical Engineering at the University of Nancy at the Groupe de Recherche en Electrotechnique et Electronique de Nancy. His interests include modeling and control of electrical machines and applied superconductivity in electrical devices.

Smail Mezani was born in Algiers, Algeria, in 1974. He received the engineer diploma and the magister degree from the University of Sciences and Technology Houari Boumediene, Algiers, Algeria in 1996 and 1999 respectively. He obtained the $\mathrm{Ph} . \mathrm{D}$. degree from the Institut National Polytechnique de Lorraine, France, in 2004.

He is currently a lecturer at the University Henri Poincaré of Nancy, France, at the Groupe de Recherche en Electrotechnique et Electronique de Nancy where his research interests include the applications of superconductors in electromechanical devices.

Abderrezak Rezzoug received the electrical engineer degree from ENSEM INPL, Nancy, France in 1972, and the Dr. Ing. diploma and the Ph.D. degree from INPL, in 1979 and 1987 respectively.

After working at the INPL as an assistant Professor until 1991, he is currently a Professor of Electrical Engineering at the University Henri Poincaré, Nancy, France. As a member of the Groupe de Recherche en Electrotechnique et Electronique de Nancy, his main subjects of research concern superconducting applications to electrical devices, and the control and diagnosis of electrical machines. 